\title{
Society for Medicinal Plant and Natural Product Research: Dr. Willmar Schwabe Research Scholarship, Egon Stahl-Award and Bionorica Phytoneering Award
}

Bibliography

DOI http://dx.doi.org/ $10.1055 / \mathrm{s}-0032-1328088$ Planta Med 2013; 79: 2-3 (c) Georg Thieme Verlag KG Stuttgart · New York . ISSN 0032-0943

Correspondence

Prof. Dr. Wolfgang Blaschek Pharmaceutical Biology Institute of Pharmacy

University of Kiel

Gutenbergstraße 76

24118 Kiel

Germany

wbla@pharmazie.uni-kiel.de

\author{
Dr. Willmar Schwabe Research \\ Scholarship for Young Scientists \\ $\nabla$
}

Awarding Institution: Society for Medicinal Plant and Natural Product Research (GA)

Endowing Sponsor: Dr. Willmar Schwabe GmbH \& Co. KG, Karlsruhe (Germany)

Endowment: 10000 EURO

Frequency: upon announcement

\section{Objective}

The aim of the Dr. Willmar Schwabe Research Scholarship for Young Scientists is to support research of young scientists, especially from developing countries in leading research institutions.

Projects focusing on pharmacological or clinical research of phytopharmaceuticals and their active substances are particularly welcome.

The award is exclusively used for travelling and living costs of the awardee and not for consumables. A duration of at least 6 months is mandatory.

\section{Criteria for application}

- Advanced (year 2 onwards) PhD students and postdocs.

- In case of similar scientific quality of applications applicants from developing countries shall have priority.

- GA membership for at least one year prior to application, with paid fees.

- Age: preferably 30 years of age (postdocs) or younger (PhD students).

- The hosting institution states in the Letter of Acceptance that it is prepared to cover the cost for the consumables used for the research project, that the student will have an adequate laboratory infrastructure and that a tutor is assigned, who supervises the applicant during his/her working period.

All documents have to be submitted to the president of the Society for Medicinal Plant and Natural Product Research in electronic form (as CD-Rs in 5 copies) until a fixed deadline.

\section{Jury}

The president of the Society for Medicinal Plant and Natural Product Research appoints at least 2 independent experts to evaluate and compare the submitted applications.

The jury will decide on the basis of the expertises and select the winner.

The jury consists of the president and the vicepresidents of the Society for Medicinal Plant and Natural Product Research, the editor-in chief of Planta Medica and a representative of Dr. Willmar Schwabe GmbH \& Co. KG.

\section{Further details}

The Dr. Willmar Schwabe Research Scholarship for Young Scientists will be bestowed in a ceremony during the Annual Congress of the Society for Medicinal Plant and Natural Product Research. The scientific results of the project shall be presented during the next annual congress preferably in a short lecture (or at least as a poster).

The awardee has to prepare a final report on the research supported by this grantand its outcome. This report has to be signed by the head of the research institution. A copy of the signed report has to be sent to the GA president and to Dr. Willmar Schwabe GmbH \& Co. KG. In case of publication of the results the award has to be mentioned in the Acknowledgement.

The award is announced via the website of GA, a circular email to all GA members, in the GA newsletter and during the Annual Congress of the Society for Medicinal Plant and Natural Product Research via an info flyer.

The deadline for submissions for the 2013 announcement is Feburary 15, 2013.

\section{Documents for application}

- Letter of Motivation (applicant)

- Letter of Support (supervisor)

- CV and list of publications

- Project description including experimental design, time schedule and justification why the research shall be performed in the respective institution

- Letter of Acceptance (hosting institution)

- Confirmation of the host institution to cover the laboratory costs (consumables)

- Specification of costs for travelling and living
Documents are to be sent to:

Prof. Dr. Wolfgang Blaschek

Pharmaceutical Biology

Institute of Pharmacy

University of Kiel

Gutenbergstraße 76

24118 Kiel

Germany

E-mail:wbla@pharmazie.uni-kiel.de 


\section{Egon Stahl-Award in Silver 2013}

$\nabla$

On the occasion of his 60th birthday, Professor Dr. Dr. h.c. mult. Egon Stahl donated a medal, a document and a monetary prize in order to recognize and promote young scientists working in the field of Pharmacognosy (Pharmaceutical Biology) and Analytical Phytochemistry.

As a rule, the silver medal and an award of $€ 3000$ should be awarded to scientists up to the age of about forty, who have published outstanding scientific work during the years following their graduation.

In 2013 the ESA Silver will be given during the 61st International Congress and Annual Meeting of GA in Münster, Germany, 1-5 Sept. 2013 (www.ga2013.org).

Members of the Society for Medicinal Plant and Natural Product Research (GA) are invited to submit nominations for candidates together with supporting data to the president of GA, Prof. Dr. Wolfgang Blaschek, Kiel.

A nomination for the prize has to include a curriculum vitae incorporating the candidate's scientific career, an index on her/his publications, and reprints of several of his/her more recent publications. All publications can be taken into consideration.

All documents have to be submitted in electronic form (as CD in 5 copies). Deadline for submission is March 15, 2013.

\section{Documents are to be sent to:}

Prof. Dr. Wolfgang Blaschek

Pharmaceutical Biology

Institute of Pharmacy

University of Kiel

Gutenbergstraße 76

24118 Kiel

Germany

E-mail: wbla@pharmazie.uni-kiel.de
Announcement Bionorica Phytoneering Award 2013

\section{$\nabla$}

BIONORICA SE is globally one of the leading companies in the area of phytotherapy, producing plant-based medicines with proven efficacy, safety and quality. BIONORICA's headquarters are located in Neumarkt i.d. Opf. (Germany/Bavaria). The company is family-owned since 80 years.

A significant focus of BIONORICA's work is concentrated on R \& D activities with annual capital investments of about $15 \%$ of the company's turnover. Although the center of all R \& D activities is in Neumarkt, BIONORICA has established further research institutes in Innsbruck (Austria) and Hong Kong. In addition BIONORICA has built a scientific network with multiple renowned institutions, organizations and scientists worldwide.

The Bionorica Phytoneering Award (BPA) acknowledges outstanding research and development with regard to medicinal plants. The award is endowed with $10000 €$.

The purpose of the award is to motivate scientists (normally younger than 45 years of age) all over the world to perform research with regard to herbal drugs focusing on the following:

Generally any new discovery and innovative application related to

- phytoanalytics/pharmacokinetics/pharmacodynamics/phytomedicine

- analytical approaches including active principles/metabolomic approaches

- research leading to the identification of new pharmacological mechanisms

- new techniques especially applied for herbal drugs

Scientists or research groups of universities and other noncommercial scientific institutions are entitled to apply. Three scientific publications on a specific topic which have been published during the last three to five years can be considered. They must be submitted in electronic form (as CD in 5 copies) until April 15, 2013 along with a CV and a list of publications to the President of the GA (Society for Medicinal Plant and Natural Product Research), Prof. Dr. Wolfgang Blaschek, Kiel.

The Bionorica Phytoneering Award will be bestowed during the 61st International GA congress in Münster (Germany), September 1-5, 2013 (www.ga2013.org). The award-winner will present the scientific results during the congress in a lecture of $30 \mathrm{~min}$ utes.

Documents are to be sent to:

Prof. Dr. Wolfgang Blaschek

Pharmaceutical Biology

Institute of Pharmacy

University of Kiel

Gutenbergstraße 76

24118 Kiel

Germany

E-mail: wbla@pharmazie.uni-kiel.de 